\title{
ARTIGO
}

\section{MÚLTIPLAS LINGUAGENS COMO METODOLOGIA PARA PENSAR O TEMPO E O ESPAÇO: O PONTO DE VISTA DAS CRIANÇAS}

Multiple speeches as a methodology to think about time and space: children's point of view

Metodología de varios idiomas como pensar que el tiempo y el espacio: punto de vista de los niños

Camila Silva Pinho

Centro Federal de Educação Tecnológica Celso Suckow da Fonseca - Brasil

Rosângela Veiga Júlio Ferreira

Colégio de Aplicação João XXIII - Brasil Universidade Federal de Juiz de Fora - Brasil

Andreia Cristina Teixeira Tocantins

Universidade Federal de Juiz de Fora - Brasil

\section{Resumo}

Este texto, que é parte de uma pesquisa de iniciação científica, discute o papel que as múltiplas linguagens ocupam no ensino de História e Geografia nos anos iniciais do Ensino Fundamental. O objetivo deste estudo é o de problematizar, por meio de narrativas de crianças, sentidos atribuídos a esses campos do saber a partir do trabalho com a literatura, o desenho e as linguagens cartográfica, lúdica e matemática. Pela interpretação dessas narrativas guardadas individualmente em portfólio, pode-se verificar que as experiências lúdicas com as múltiplas linguagens foram as que desencadearam aprendizagens, constituindo-se como uma metodologia a ser considerada nas práticas pedagógicas.

Palavras-chave: Espaço. Múltiplas linguagens. Narrativas de crianças. Tempo.

\begin{abstract}
This text, part of a scientific initiation research, discusses the role that multiple languages take in the teaching of History and Geography in the early years of elementary school. The aim of this study is to discuss, through child narratives, the meanings granted to these fields of knowledge, from the work with literature, drawing and cartographical, playful and mathematical languages. It can be seen, by interpreting these stored narratives individually in
\end{abstract}


portfolio, that the playful experiences with multiple languages were the ones that triggered learning, establishing itself as a methodology to be considered in pedagogical practices.

Keywords: Child narrative. Multiple languages. Space. Time.

\section{Resumen}

Este texto, que es parte de una investigación de iniciación científica, discute el papel que ocupan en las múltiples lenguajes en lo enseñanza de la Historia y de la Geografía en los primeros años de la escuela primaria. El objetivo de este estudio es problematizar a través de las narrativas de los niños los significados atribuidos a estos campos de conocimiento por medio de lo trabajo con la literatura, el diseño y lenguajes cartográfica, lúdica y matemática. Por la interpretación de estas narrativas almacenados individualmente en un cuaderno, se puede observar que las experiencias lúdicas con múltiples lenguajes fueron que condujo el aprendizaje, estableciéndose como una metodología para ser considerada en las prácticas pedagógicas.

Palabras clave: Espacio. Múltiples lenguajes. Narrativas de los niños. Tiempo.

\section{Introdução}

Este trabalho discute o papel das múltiplas linguagens na compreensão e na problematização de conceitos do campo da História e da Geografia, desde os anos iniciais do Ensino Fundamental, objetivando constituir formas outras de entendimento do mundo. $\mathrm{O}$ texto, resultado de uma pesquisa desenvolvida no Colégio de Aplicação João XXIII/UFJF, busca refletir sobre o papel que o ensino de História e Geografia desempenha na formação do leitor. Tal reflexão sustenta-se a partir da importância dada ao fato de a criança estabelecer hipóteses, observar, descrever, representar e construir explicações sobre o que vê e sente, entrecruzando as experiências de vida e o conhecimento histórico e geográfico com o universo de múltiplas linguagens ${ }^{1}$.

Para tanto, optamos por analisar as narrativas produzidas pelas crianças do $5^{\circ}$ ano do Ensino Fundamental partindo de um disparador de memória. Tais narrativas foram oriundas das discussões em sala de aula a partir do contato com um portfólio elaborado por esses estudantes nas aulas do módulo Educação Geográfica e Histórica pelas imagens literárias: múltiplas linguagens, em anos anteriores ${ }^{2}$. Esse módulo, que é trimestral, tem por objetivo

\footnotetext{
${ }^{1}$ Esta pesquisa deu origem à monografia de Silva (2014) cujos resultados parciais foram colocados em debate no $6^{\circ}$ Seminário Brasileiro $3^{\circ}$ Seminário Internacional de Estudos Culturais e Educação.

${ }^{2} \mathrm{O}$ módulo se constitui em um modelo de aula realizado uma vez por semana, durante 45 minutos, nas turmas da instituição, com diferentes temas. Cada módulo se configura, em sua maioria, em um trimestre, podendo ser trabalhado nas três turmas de cada ano (série) durante o ano letivo. Em última instância, informamos ao leitor que as turmas no Colégio de Aplicação mantêm um padrão de 30 alunos em cada.
} 
provocar espaços de reflexão entre os estudantes dos anos iniciais do Ensino Fundamental sobre formas de conhecer o mundo pelos campos de ensino da História e da Geografia. A esquisa que dá origem a este texto foi desenvolvida a partir das práticas pedagógicas desse módulo realizadas durante os anos de 2011 e $2012^{3}$.

Em linhas gerais, com a realização da investigação, procuramos entender como as experiências com os encontros do módulo contribuíram para a construção de aprendizagens históricas e geográficas. Nesse contexto, trabalhamos com a hipótese de que, no ensino dessas áreas de conhecimento, as diferentes linguagens podem se constituir como uma prática importante na produção de sentidos sobre o tempo e o espaço.

A fim de subsidiar essas análises das produções das crianças, trazemos, na primeira parte deste texto, o referencial teórico que discute as relações temporais e espaciais que constituem o homem no mundo, por serem pontos definidores das âncoras que sustentam a educação do olhar das crianças nos anos iniciais do Ensino Fundamental. A narrativa como perspectiva metodológica é o tema central da segunda parte deste trabalho na qual apresentamos a concepção segundo a qual analisamos os textos produzidos pelas crianças, compreendendo-os como fonte da pesquisa. Na sequência, procedemos à exposição das análises sustentadas em temas definidos a partir da interação do pesquisador com as narrativas produzidas pelas crianças no período supracitado. Tais análises nos permitem afirmar que a linguagem literária representa um ponto a ser considerado no processo de relação da criança com o conhecimento, possibilitando, inclusive, o seu contato com outras linguagens.

\section{O estudo do tempo e do espaço: desafios para o ensino de história e geografia nos anos iniciais do ensino fundamental}

O objetivo aqui é pensar sobre o significado de educar para a compreensão do tempo e do espaço no intuito de refletir sobre o ensino das disciplinas de História e de Geografia nos anos iniciais do Ensino Fundamental.

Nessa perspectiva, defendemos que estudar História implica analisar o que acontece, o que aconteceu e o que poderá acontecer com os homens a partir de diferentes pontos de vista, compreendendo a importância das fontes para entender uma dada temporalidade. Assim, torna-se possível desenvolver uma criticidade diante da História, de modo que o passado

\footnotetext{
${ }^{3}$ Importante informar ao leitor que a professora que ministrou o módulo de História e Geografia nos $2^{\circ}$ e $3^{\circ}$ anos - 2011 e 2012, respectivamente -, foi a mesma que lecionou História e Geografia na turma do $5^{\circ}$ ano - 2014 que produziu as narrativas fontes desta pesquisa.
} 
adquire sentido para os educandos, como sujeitos históricos situados no presente. Noutras palavras, significa tomar o passado como momento capaz de produzir sentidos para os sujeitos que vivem o tempo atual (MIRANDA; ALMEIDA, 2010).

A partir do exposto, o que defendemos é que a utilização de diversas fontes e linguagens, com o intuito de compreender um tempo histórico, pode auxiliar no entendimento de acontecimentos, possibilitando o estabelecimento de diálogos temporais através do acesso a fontes que coloquem, em dúvida, certezas. Entendemos essas fontes como produções humanas, originárias da relação do homem com uma dada temporalidade.

Nesse processo de se educar para a compreensão da História, oportunizar que as crianças explorem seus conhecimentos acerca de determinados assuntos é de suma importância, uma vez que elas trazem consigo uma gama de conhecimentos de mundo que podem ser incorporados ao processo de ensino. Trabalhar a partir dos significados que as crianças atribuem ao tempo a partir de sua perspectiva no presente faz com que elas se sintam parte da história (MIRANDA; ALMEIDA, 2010).

Uma das formas de desenvolver tal trabalho é através de práticas de memória. Essa dinâmica permite que os alunos se compreendam por meio de suas próprias representações. Isso porque a memória é uma característica pessoal que mostra como o ser humano se relaciona com o passado e que elementos ele considera significativos. Dessa maneira, a narrativa encontra na memória uma fonte de produção que pode potencializar dinâmicas de lembranças e esquecimentos.

Nesse sentido, todos têm algo a ser lembrado ou esquecido durante a vida. Sua intencionalidade depende da relação que estabelecemos com as pessoas, com os lugares, tendo em vista que, quando narramos, fazemos escolhas sobre o que contar, estabelecendo uma seleção nas memórias. Narrar histórias em aulas é uma forma de relatar o passado, de modo que, durante o percurso, relações sejam estabelecidas. Logo, as narrativas surgem, muitas vezes, mediadas por memórias de um tempo vivido, permitindo que a pessoa retome vivências individuais, identificando elementos que as tornam coletivas, tal qual ocorreu no módulo.

No que se refere à Geografia, defendemos um ensino que busque, primordialmente, compreender as relações existentes entre o homem e o espaço que o rodeia, considerando, para isso, a realidade concreta do espaço vivido por cada sujeito, tanto na dimensão global quanto na local. A concepção de ensino de Geografia que sustenta este estudo é a de que é preciso compreender que as paisagens que nos cercam representam acontecimentos ocorridos 
ao longo do tempo histórico em um determinado lugar, constituindo as paisagens que formam o espaço.

Nesse sentido, em confluência com Straforini (2001), a criança forma-se como leitora, geograficamente falando, na medida em que passa a compreender o espaço vivido por ela, enfrentando desafios na busca pelo entendimento de formas de registrar o mundo ao seu redor. São linguagens que podem encontrar significação na medida em que as representações gráficas e cartográficas possam ser objeto de diálogo nas práticas de leitura do espaço (ALMEIDA, 2001).

A linguagem gráfica coloca-se como instrumento essencial para perceber a noção de espaço que é estabelecida pela criança, sobretudo através do desenho. O desenho pode surgir pelo prazer em riscar, em que tais rabiscos representam objetos constituídos de significados, ou mesmo quando requerem uma explicação oral das crianças, possibilitando o estabelecimento de relações (ALMEIDA, 2001). Partimos do pressuposto de que as crianças representam, em desenhos, suas experiências com o lugar, iniciando, dessa forma, um processo de desenvolvimento da linguagem cartográfica que pode e deve ser ensinada nas escolas a partir dessas e de outras representações canônicas (mapas em geral).

A essas representações somam-se as linguagens fotográficas e matemáticas que possibilitam um alargamento na visão do espaço. As fotográficas podem educar o olhar da criança para permanências e/ou mudanças dos lugares observados. A matemática pode educar o olhar para uma visão global dessas mudanças, quando agrupa informações, oportunizando comparações sobre um conjunto de dados.

Concebemos, portanto, um ensino para além do acervo de conteúdos, o que poderá ser alcançado através do estabelecimento das relações entre as identidades individuais, sociais e coletivas. Assim também acontece ao interagirmos os fatos particulares com o contexto social mais amplo, a partir da construção das noções de diferença, semelhança, continuidade e permanência, com o uso de metodologias diversas, do significado de letramento e, por conseguinte, da utilização das múltiplas linguagens e da construção de narrativas como metodologia de trabalho.

As colocações anteriores, que remetem a questões centrais do ensino de História e Geografia para os anos iniciais, encontram na memória um elemento transversal, por permitir dialogar com tempos e os espaços. As memórias que contam a história das aulas do módulo e a experiência íntima e coletiva dos alunos com elas são permeadas de lembranças e esquecimentos. Nesse sentido, as narrativas foram utilizadas como recursos que auxiliaram no processo de construção identitária e de recuperação de uma memória individual e coletiva, 
constituindo-se como um instrumento no trabalho com o ensino de História e também de Geografia nos anos iniciais do Ensino Fundamental. Tal perspectiva evidencia uma compreensão de ensino como prática reflexiva dialógica, inacabada, integrada; um processo contínuo, construído e reconstruído, conforme apresentado a seguir.

\section{Narrativas de crianças: uma escolha metodológica}

O objetivo neste tópico é apresentar o referencial teórico-metodológico escolhido: a narrativa, bem como os procedimentos metodológicos que sustentaram a defesa do referido módulo como uma modalidade de ensino a ser considerada para o desenvolvimento de atividades pedagógicas. Tal escolha metodológica decorre do fato de crianças poderem narrar sobre suas experiências literárias, constituindo-se em fontes de pesquisa materializadas a partir do uso das suas produções orais e dos registros pessoais escritos por elas.

Entendemos a narrativa como possibilidade interpretativa de diferentes pontos de vista. Além desse caráter reflexivo, a narrativa como metodologia requer do pesquisador a observação atenta ao contexto em que a pesquisa se realiza e aos efeitos mais amplos das relações estabelecidas, atentando para questões que antes passavam despercebidas (MELLO; RODRIGUES; MACHADO, 2010). Nessa perspectiva metodológica, é importante enfatizar que se trata de um adulto interpretando textos produzidos por crianças, buscando captar seus pontos de vista. O esforço, nesse caso, é o de buscar compreender implícitos das colocações das crianças, destacando-se o fato da dificuldade de deslocamento desse lugar de adulto.

A escolha por analisar as narrativas produzidas pelas crianças, para compreender os sentidos que atribuem para as discussões oriundas do campo de ensino das Ciências Humanas, justifica-se pelo fato de buscarmos sustentar a hipótese de que o trabalho que vimos realizando no módulo contribui para a formação de um leitor que reflete sobre questões postas no mundo.

Em confluência com as discussões de Chaves (2014), a narrativa, neste texto, é concebida como meio de informar os resultados do trabalho de uma das pesquisas desenvolvidas no módulo - uso das múltiplas linguagens como uma possibilidade metodológica para o ensino de História e Geografia. A partir disso, é vista como meio para pensar e entender melhor o ensino e as práticas educacionais exercidas nesse módulo, bem como para auxiliar na compreensão do ensino dessas áreas do conhecimento, abrindo novas perspectivas de pesquisas. 
Consideramos, para fins deste texto, as dimensões da sociabilidade e da temporalidade narrativa como elementos que propiciaram a identificação de possibilidades e limites da proposta apresentada.

A sociabilidade é definida em dois aspectos: as colocações das crianças nas suas experiências pessoais com o módulo em diferentes tempos - condições pessoais - e o ambiente no qual os diferentes encontros aconteceram - condições sociais. As condições pessoais vistas como aquelas que remetem a sentimentos, e as sociais, ao ambiente no qual e sob o qual as narrativas das crianças foram produzidas (MELLO; RODRIGUES; MACHADO, 2010).

Já no que diz respeito à temporalidade, é preciso, a nosso ver, entender o movimento que as crianças empreenderam no momento em que produziram os registros do portfólio, olhando, portanto, para o passado. Da mesma forma, interpretar essa definição a partir de perspectivas futuras dadas pelo movimento do presente - produção da narrativa. O pesquisador olha, então, para trás e para frente.

Com base nessas questões metodológicas, buscamos analisar as narrativas produzidas pelas crianças em situações de interação com a leitura literária, que desencadeou o registro de outras linguagens. Acreditamos, de acordo com Vygotsky (2007), que é pela interação que o ser humano se constrói, transforma-se, cria e recria a si mesmo, dialogando e criando significados para os seus atos e falas. Na escola, as palavras funcionam como meio de comunicação, como modo de organizar as ações e interações, como portadoras de novos conhecimentos e como objeto de ensino. Nesse sentido, refletir sobre o que se leu e escreveu, como e sob que condições se aprendeu esse bem cultural, pode auxiliar no processo de letramento. O que se discute aqui é que a compreensão histórica e geográfica, pela via das múltiplas linguagens, envolve aspectos sociais, históricos, culturais, linguísticos, cognitivos e afetivos, o que implica considerar o contexto sociocultural dos estudantes.

Temos como pressuposto teórico que as mediações promovidas nas práticas de leitura do módulo devem possibilitar processos de reelaboração estabelecidos a partir de zonas de desenvolvimento proximal - distância entre o nível de desenvolvimento real, que se costuma determinar através da solução independente de problemas, e o nível de desenvolvimento potencial, determinado através da solução de problemas sob a orientação de um adulto ou em colaboração com companheiros mais capazes (VYGOTSKY, 2007).

As interpretações dessas narrativas nos permitiram elencar pontos centrais de análise pautados nas experiências das crianças com os livros de literatura, que produziram referências para pensar sobre os sentidos que atribuíram para essas vivências literárias. 


\section{"O dia que mais me marcou foi..." : o que disseram as crianças sobre suas experiências ${ }^{5}$}

As narrativas produzidas pelas crianças sobre os momentos vividos e rememorados nos módulos constituíram-se como subsídio para as análises deste trabalho. A organização das fontes da pesquisa foi definida a partir do nosso olhar de pesquisadoras para os discursos das próprias crianças, buscando identificar significados que atribuíram para o que ocorrera nos encontros dos módulos, mediados tanto pela linguagem literária quanto pela gráfica, fotográfica, matemática e cartográfica. Para tanto, elencamos as seguintes categorias: Lembrar-Esquecer: as permanências, continuidades e descontinuidades; Espaço - tempo: os lugares em que vivemos; Literatura infantil: as histórias que nos marcam. O que estabelecemos para sustentar as análises desses três pontos foi o entendimento das narrativas produzidas pelas crianças a partir do recorte de acontecimentos que ocorreram posteriormente (para frente) e anteriormente (para trás), para pensar a dimensão do tempo. Na mesma medida, as sensações pessoais (para dentro) e os sentidos dados a partir de experiências coletivas (para fora), para organizar as discussões sobre o espaço.

\section{Lembrar- Esquecer: permanências, continuidades e descontinuidades}

O que lembramos e por quê? O que esquecemos e por quê? Perguntas que encontram nos sentidos que conferimos às nossas experiências uma dimensão de explicabilidade. Entendemos que tanto os objetos quanto as pessoas e os lugares potencializam essas dinâmicas operadas na memória porque dizem de experiências marcadas no e pelo tempo. A memória remete a um tempo passado que pode ser ressignificado pelas experiências do presente, tal qual ocorreu com o portfólio em que foram registradas as memórias das vivências em tempos cronológicos distintos.

Ao ter em mãos o artefato que disparou memórias, podemos observar que, para algumas crianças, determinadas lembranças retornaram ao pensamento. Para Miranda e Almeida (2010, p. 72), “lembranças - ou aquilo que é guardado - são 'náufragos’ em um mar de esquecimentos". Portanto, aquilo que se seleciona é algo muito pequeno, se considerarmos a complexidade e a profundidade da vida humana no tempo. Desse modo, percebemos que nem tudo se tornou significativo para todos, que os momentos vividos são, algumas vezes,

\footnotetext{
${ }^{4}$ Trecho presente em um número significativo de narrativas.

${ }^{5}$ Informamos que os nomes dos alunos são fictícios e que apresentamos as falas em itálico.
} 
deixados de lado por uns e por outros, não. Tal seleção não encontra motivo previamente definido. Mesmo variando em termos de explicação, as seleções ocorrem, a nosso ver, pelos significados atribuídos pelos sujeitos a partir da relação com o objeto ou uma situação em determinado lugar e tempo.

As narrativas das crianças apontaram para a importância da ludicidade no processo de ensino e aprendizagem, tanto no módulo do $2^{\circ}$ ano quanto no do ano subsequente. As aulas em que elas puderam brincar e levar brinquedos tornaram-se as mais significativas, permeando fortemente suas memórias, o que possibilitou lembranças sobre a construção de um brinquedo - a peteca-, assim como o livro de literatura que desencadeou a vivência lúdica - Brincadeira de todos os tempos (RAMOS, 2011). O encontro a que se referem esses estudantes, ocorrido quando estavam no $2^{\circ}$ ano, teve início com uma pesquisa sobre as brincadeiras preferidas do tempo dos pais. Nessa enquete, jogar peteca foi uma das práticas que apareceu de forma reiterada, o que acabou gerando a atividade de produção da peteca de jornal com os alunos que foram brincar na quadra dessa brincadeira que atravessa gerações.

Tal constatação evidencia que proporcionar momentos lúdicos para as crianças contribui para um aprendizado significativo, possibilitando o estabelecimento de relações (FREITAS; AGUIAR, 2012), como nos disse o aluno Leon, ao afirmar que "O dia que mais me marcou foi a última aula que podia trazer um jogo". Esse estudante refere-se a uma tarefa realizada quando era aluno do $3^{\circ}$ ano em que o tema central fora a brincadeira, estabelecendo um diálogo entre presente e passado, o que culminou com a experiência por ele relatada.

O que consideramos importante destacar com relação ao trabalho com o lúdico é que ele proporciona às crianças momentos de interação e socialização, possibilitando, além disso, que elas pensem, questionem, solucionem os problemas que possam vir a suceder no decorrer das brincadeiras.

A narrativa oral de uma criança, produzida a partir daquele momento de interação na retomada do portfólio, na roda de conversa, chama-nos a atenção. Ao rememorarem sobre os programas favoritos, um dos alunos relata que havia alguns programas de que não se recordava que existiam, dos quais, no período da realização da atividade, "ele gostava, mas que hoje não gosta mais". Partindo desse relato, entendemos ser importante problematizar sobre outro ponto que suscita reflexões sobre o ensino de História, a saber: permanências, continuidades e descontinuidades que possibilitam refletir sobre a passagem do tempo. No decorrer dos anos, muitas coisas mudam, como gostos e preferências, por exemplo. Isso porque o tempo passa, a sociedade se modifica e novos acontecimentos fazem com que os seres humanos vivenciem e experimentem novas situações. 
Ao ler as narrativas produzidas pelas crianças, após o contato com o portfólio, uma narrativa em especial chamou a nossa atenção. $\mathrm{O}$ aluno Eddie, ao ser convidado a olhar para o tempo que se passou e a escrever sobre o que se recordava em relação às aulas do módulo, afirmou:

Para mim fazer essa história foi muito difícil porque não tenho muitas recordações de quando eu era do $2^{\circ}$ e $3^{\circ}$ ano. Também porque não consegui decidir sobre o que escrever, pensei muito e nada. Pedi ajuda para algumas pessoas, mas nem assim. Cheguei à conclusão que nem sempre é fácil lembrar ou muito menos falar de alguma coisa.

Nessa narrativa, o que nos chama atenção é o fato de o aluno, mesmo tentando reconstruir os acontecimentos coletivamente, não consegue ver razão para escrever a narrativa solicitada, pelo simples fato de não ter atribuído sentido para algo de que não se lembra. $\mathrm{O}$ que pode ser entendido como uma tarefa pouco significativa ao aluno é por nós entendida como potente para pensar o ensino de História.

A ênfase, no caso das colocações discutidas pelo conjunto de alunos sobre a narrativa do Eddie, foi que ele produziu uma narrativa que marcou sua relação de pouco sentido com as tarefas realizadas no módulo. Quais fatores provocaram esse não interesse não foram levantados, mas a maioria das crianças entendeu e respeitou a negação do colega em lembrar, o que não o impediu de, à maneira como foi possível, realizar a atividade proposta. Para esse aluno, o que vivenciara durante as aulas do módulo ficara perdido em suas lembranças e permanecera tão profundo a ponto de não ser tocado através dos artefatos produzidos por ele mesmo. Tal colocação nos faz refletir sobre a função de seletividade da memória.

Mesmo representando uma minoria dentre o universo de alunos que se recordam de algumas experiências, consideramos relevante trazer essa colocação por representar outro ponto de vista para a dinâmica instituída no módulo. Tal perspectiva aponta para como é difícil pensar o singular em um ambiente plural, o que nos desafia constantemente como professores e pesquisadores.

Dessa forma, podemos perceber que conduzir as crianças a elaborarem questões que as façam evocar conhecimentos do passado para compreender o tempo presente significa gerar sentidos sobre o presente. Desse modo, as crianças passam a dialogar através dos deslocamentos temporais entre presente e passado.

Podemos observar que, ao longo desses anos, as crianças, envolvidas nas atividades do módulo, conseguiram construir noções de temporalidade através da compreensão das 
continuidades e descontinuidades envolvidas no processo de constituição de uma memória, de uma historia individual e coletiva.

\section{Espaço e tempo: os lugares em que vivemos}

No que se refere ao tempo, entendemos que, apesar da complexidade, ele pode ser experienciado pela criança. $\mathrm{O}$ estudo da temporalidade torna-se, portanto, necessário, podendo e devendo ocorrer a partir de diferentes pontos de vista: na dimensão da passagem do tempo, realizando operações de seriação, tendo como referência o tempo do calendário; na simultaneidade do tempo, tendo como eixo, nesse caso, as experiências e as reflexões sobre formas de comparar acontecimentos em um dado tempo (MIRANDA; ALMEIDA, 2010).

Ao abordar a temporalidade, o espaço surge simultaneamente, em decorrência da dificuldade em separar tais conceitos. Muitos dissociam o espaço da História, entendendo-o como um conceito próprio ao campo da Geografia por remeter a um lugar (ou lugares) de um dado acontecimento. Entretanto, as relações entre os seres humanos ocorrem em um determinado lugar e este, por conseguinte, pode ser entendido em suas mudanças e permanências temporais e espaciais.

Pelas nossas análises, a compreensão das relações entre tempo e espaço esteve presente de forma relacionada nas aulas mediadas pelo portfólio. As atividades realizadas proporcionaram, através das múltiplas linguagens (desenhos, objetos, fotos, poemas), uma percepção das demarcações temporais que, por vezes, foram realizadas em lugares que despertaram uma relação de proximidade entre estudantes e objeto a ser estudado.

Interpretar narrativas que trazem conhecimento de um tempo passado desempenha efeito formativo na condição de pensar historicamente, possibilitando estabelecer relações com a contemporaneidade, o que significa compreender presente e passado em uma perspectiva de complementaridade. Constatamos, em Miranda e Almeida (2010), a preocupação em nos fazer refletir sobre a importância que olhar para o espaço a partir da potência formativa que esse lugar pode abarcar: objetos dizem de um tempo; roupas dizem de um tempo; o modo de falar diz de um tempo... São essas noções de mudança temporal que possibilitam à criança compreender e perceber que existe um tempo anterior a ela, sendo esse tempo registrado pelas relações que estabelece com sujeitos, objetos e lugares.

Poder estar em contato com brincadeiras advindas de gerações anteriores evidencia marcas de temporalidade. Muitas delas foram inventadas há séculos e continuam sendo passadas de geração em geração, por ser algo significativo para determinado grupo de 
pessoas. A partir dessa percepção, buscamos destacar, com base em Miranda e Almeida (2010, p. 21), que é necessário oportunizar às crianças “experimentar narrativas de vidas as quais tenham a ver com outros contextos históricos que não os do presente imediato e que isso não precisa, necessariamente, vir didatizado sob o fio de qualquer forma de cronologia".

Fazer o levantamento das brincadeiras que as pessoas das gerações passadas realizavam pode auxiliar a criança na compreensão das mudanças que ocorreram no decorrer do tempo: o que seus familiares gostavam em sua infância não necessariamente constitui a mesma preferência das crianças atualmente, embora o contrário também possa acontecer. São essas noções de mudança e/ou permanência que possibilitam à criança compreender e perceber que existe um tempo anterior a ela e que ela própria se constitui como parte de um tempo. A troca de experiências provoca, nesse caso, a compreensão de aspectos do passado presentes em objetos, lugares e fotografias que auxiliam as crianças a educar seus olhares sobre um tempo passado.

Nas análises das narrativas, pudemos perceber a marca do passado nas falas das crianças, quando, por exemplo, observamos a escolha de verbos no tempo passado quando se referiam ao dia em que "pediu”, "brincou”, "resolveu”, o que aponta para a clareza de que o fato ali narrado acontecera em outro tempo e, quando retomado, ganhava outra autoria: a deles próprios. Em expressões como “o dia”, “eu me lembro”, nota-se o estabelecimento de relações temporais contínuas, compondo entendimentos daquilo que permaneceu nas memórias dessas crianças, ou seja, daquilo que, de alguma forma, fora significativo para elas.

Ao relatarem momentos de suas vidas pessoais, as crianças fizeram relações com o que viveram e o tempo em que ocorreram as experiências. Podemos observar essa relação temporal na colocação de Ingrid, ao afirmar que, "quando estava nas férias, alguns anos atrás, eu e minha família [...]”, ou ainda quando Brad nos diz que "meu pai e minha mãe se encontraram e namoraram depois de alguns meses o bebê foi crescendo até que nasceu”.

No que se refere ao espaço, cabe relatar que as aulas do módulo não ocorreram, em sua maioria, na sala de aula, tendo sido algumas atividades realizadas no anfiteatro da escola, na telemática ou ainda no pátio. Ao rememorarem as experiências vividas, essas ocupações dos diferentes espaços de realização das atividades estiveram presentes nas narrativas de algumas crianças, como pode ser lido em um pequeno trecho das narrativas de Lílian e Robert, respectivamente, "encontraram a joaninha em um lugar do anfiteatro"; "eu me lembro de quando fomos para o anfiteatro".

Percebemos que as experiências apresentam dimensões variadas a partir do ponto de vista sob o qual a olhamos. Destacamos, em especial, que a saída do ambiente da sala de aula 
foi entendida por um número significativo de alunos como um momento lúdico. Isso pode ter contribuído para que tenha aparecido de forma reiterada a descrição da experiência vivida nesses lugares, quando em comparação com as que foram realizadas na sala de aula. O que constatamos é que, ao mudar de ambiente para a realização de uma atividade, os lugares foram marcados nas narrativas.

Cabe relatar que uma tarefa que fora realizada no anfiteatro, reiteradamente mencionada pelas crianças, aparece relacionada ao trabalho com o livro A casa da Joaninha (FREIRE, 1982). Identificamos que tal trabalho oportunizou o uso de linguagens cartográficas e matemáticas por meio de uma reflexão sobre localização, que também foi considerada nas narrativas das crianças. Nessa atividade, os alunos deslocaram-se pela escola e, para chegar ao local, tiveram que seguir orientações geográficas para saber onde deveriam ir. Foram utilizadas noções de lateralidade (direita/esquerda) e conhecimentos matemáticos, segundo os quais tiveram que contar passos na direção solicitada, conforme pode ser observado na figura a seguir que representa uma das atividades que compõe o portfólio.

\section{Figura 1 - Instruções para chegar à Joaninha no Anfiteatro}

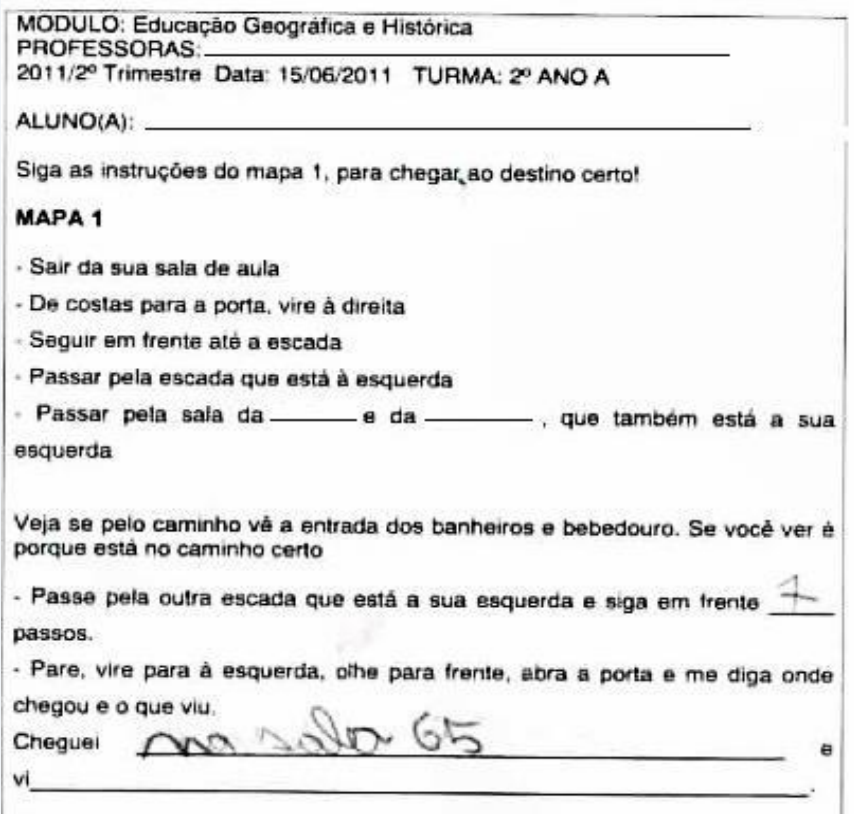

Fonte: Arquivo do autor (2011).

Entendemos ser importante enfatizar que tal tarefa foi realizada com metade da turma. Notamos que, entre os estudantes que formavam o grupo de alunos que chegava à sala 65 , descrita na imagem escolhida, não havia menção ao espaço físico, embora eles narrem a experiência de andar pela escola, seguindo as orientações, e de encontrar a joaninha. O grupo que foi ao Anfiteatro, sala 33, narrou essa experiência remetendo-se ao lugar, como pode ser 
lido na colocação da Lílian ao afirmar em sua narrativa que "tinha escondido a joaninha em um lugar do anfiteatro e fomos e a joaninha estava escondida embaixo da cadeira".

A experiência com a atividade da joaninha aponta para a dimensão de ludicidade, o que sustenta o argumento de que as colocações reiteradas das crianças sobre o lugar e sobre esse trabalho em especial foram significativas, a ponto de, inclusive, aparecerem conceitos históricos e geográficos marcados nas narrativas.

Nessa interação, destacamos a potência formativa que o trabalho com as linguagens pode atribuir ao ensino desses campos do conhecimento, entendendo ser a escolha metodológica uma estratégia importante para educar o olhar da criança. Dentre tais linguagens, destacamos o papel que a literatura pode desempenhar no processo de problematização dos conceitos históricos e geográficos.

\section{Literatura infantil: as histórias que nos marcam ${ }^{6}$}

De acordo com Coelho (2000), a literatura infantil é arte, é um fenômeno de criatividade que representa o mundo, o homem e a vida através de palavras. Além disso, pode ser entendida como uma linguagem motivadora e desafiadora que permite ampliar o conhecimento. Com base nessa compreensão do papel da literatura, entendemos tratar-se de uma estratégia importante nos anos iniciais do Ensino Fundamental.

A referência a alguns dos livros de literatura que foram trabalhados em detrimento de outros foi um fator que nos chamou atenção. A pergunta que nos moveu foi: por que tais escolhas? Ao analisar as produções individuais das crianças, constatamos que, ao rememorarem e narrarem suas recordações sobre alguns livros, ficou evidente a potência do trabalho com a linguagem literária no processo de ensino-aprendizagem. Nas falas dessas crianças, a presença da literatura é considerada. Cabe relatar, todavia, que os livros escolhidos como mote para compor as narrativas foram aqueles que possibilitaram, de alguma forma, experiências lúdicas, conforme discutido no subitem anterior.

Nessa mesma linha interpretativa, chamou nossa atenção a referência ao livro LigaDesliga (FRANCO; PIRES, 2003), que traz discussões sobre outras formas de brincar, fazendo uma crítica ao tempo que as crianças passam diante da televisão. A atividade proposta após a leitura do livro foi uma pesquisa sobre gostos, preferências e hábitos das

\footnotetext{
${ }^{6}$ Nos módulos foram trabalhados os seguintes livros de literatura: A Pirilampéia e os dois meninos de Tatipurum; Guilherme Augusto Araújo Fernandes; A casa da Joaninha; Quando eu comecei a crescer; Todo mundo tem família; As famílias do Mundinho; Brincadeiras de todos os tempos e Viver a Poesia. Truques Coloridos; Liga-Desliga e Receita de Brincadeira.
} 
crianças, na qual os alunos puderam relatar sobre suas brincadeiras, jogos e programas preferidos. Na narrativa da aluna Cristine, pudemos constatar como o livro poderia ser “divertido e gostoso de se escutar". Além disso, ao narrar sobre o dia em questão, a aluna demonstra, em seu texto, a importância de se escutar o que pensam as crianças, permitindo que tragam elementos do seu cotidiano para serem discutidos em sala de aula: "Eu me lembro quando escrevemos programas de televisão que mais gostamos eu lembro que eu ainda gostava de 'Famboy e Chum Chum' confesso ainda vejo 'Famboy e Chum Chum'é legal!' (sic). Dessa maneira, o aluno passa a se sentir parte do meio e da construção do conhecimento. Segundo Miranda e Almeida,

[...] tomar a realidade do aluno como ponto de referência, não significa restringir o programa de História a essa realidade, tampouco fortalecer o argumento e a tendência de que o ensino deve se organizar a partir de círculos concêntricos estabelecidos do espaço-tempo mais próximo ao mais distante. Contrariamente a isso, é preciso construir pontes entre aquilo que o indivíduo não conhece - um tempo ou contexto histórico distante, não vivido - e aquilo que é palatável para ele, tal como a sua vida e o contexto histórico no qual ele se insere e que é pautado por forte presença dos aspectos culturais e materiais do mundo sobre o lugar de vivência. (MIRANDA; ALMEIDA, 2010, p. 17) (grifos do autor).

Ao narrarem suas lembranças acerca das aulas do módulo, algumas crianças não descreveram o que se recordaram, mas criaram uma história a partir de suas reminiscências. De acordo com Miranda e Almeida (2010, p.36), "a literatura tende a exercer um papel fundamental na possibilidade de ativar a dimensão imaginativa associada à capacidade narrativa, seja esta pautada na oralidade ou na construção escrita", tal qual pode ser constatado na narrativa da aluna Angelina, que escreveu uma história baseada na situação lúdica de produção da peteca, como já destacado neste texto, conforme pode ser lido na íntegra a seguir.

Em um dia da semana, a turma terceiro $\mathrm{C}$, teriam aula de módulo. Mas naquele módulo debatiam sobre as brincadeiras, então os alunos foram para o anfiteatro (sala de vídeos) para fazer uma peteca de jornal. Aí um menino disse:

- Porque peteca de jornal, poderíamos comprar uma. - Ele perguntou em alto e bom som. A professora respondeu:

- Não acha legal fazer uma peteca de jornal. Na minha opinião uma peteca comprada é sem graça, mas uma peteca feita por vocês tem graça, porque vocês ficam na expectativa.

O menino calou-se, mas aquilo tinha deixado-o tão bravo que de repente sem a professora perceber ele foi lá e rasgou todas as petecas. A meninada ficou tão triste que começou a falar para professora. A professora não sabia o que fazer. E falou: 
- Atenção, pode deixar que eu vejo isso melhor.

O menino todo contente foi para casa, chegando em casa contou para a sua família sua artimanha, a família falou para o menino:

- Meu filho nunca mais faça isso. O mesmo trabalho que você teve para fazer sua artimanha os donos das petecas tiveram para construir.

$\mathrm{O}$ menino pensou naquilo a noite inteira. $\mathrm{E}$ chegou uma hora que não aguentava mais, aí resolveu pegar vários jornais para fazer as petecas. No dia seguinte entregou para todas as pessoas suas petecas. A professora viu seu gesto e ficou impressionada. Na hora do recreio eles foram brincar com suas petecas. E ele passou a respeitar seus amigos e professores.

Destacamos o sentido que Angelina atribuiu à atividade em que, enfatizando marcações temporais e espaciais, retomando a experiência, faz o movimento para trás e para frente, rompendo com a linearidade do processo, estabelecendo, assim, sentido para o que vivera. Nesse percurso reflexivo, cria, a partir da experiência de fazer e brincar com a peteca do jornal, uma situação na qual a peteca é destruída e restituída, partindo do relato de uma situação que pertence ao cotidiano escolar e não escolar: o dos conflitos.

Cabe destacar que, apesar de a maioria das crianças utilizar o recurso da descrição para narrar suas memórias, a dimensão do imaginário foi também considerada. Acreditamos, em consonância com as discussões de Miranda e Almeida (2010), que é de suma importância que as situações de educar para a compreensão de conceitos históricos e geográficos sejam, especialmente, sustentadas pelo movimento de escuta dos sentidos que as crianças estabelecem.

O que discutimos neste subitem é que o texto literário proporciona diversas possibilidades de ver o mundo. Portanto, pode ser considerado como uma linguagem que pode auxiliar na disseminação do conhecimento de modo que o sujeito possa refletir sobre questões que atravessam o seu cotidiano. O que as crianças disseram e os sentidos que atribuíram nos instigam a pensar no quanto a literatura, em especial, e outras linguagens podem atribuir sentido para práticas pedagógicas.

\section{Algumas considerações}

A análise das narrativas permite-nos afirmar que o trabalho com as múltiplas linguagens foi significativo para a maioria das crianças e, para cada uma, de uma maneira singular. Compreendemos ainda sua importância para o processo de ensino aprendizagem, em que as relações vividas nas atividades ajudaram as crianças a se constituírem como sujeitos ativos, pensantes, que estabelecem vínculos e que aprendem a se posicionar diante de diversas questões indispensáveis para sua formação como leitores autônomos. 
Nesse contexto, as múltiplas linguagens mostraram-se potentes para a aprendizagem histórica e geográfica. Cabe relatar que as crianças compreenderam questões temporais e espaciais através de suas experiências. Portanto, a literatura e outras linguagens utilizadas nas aulas consubstanciaram-se como importantes alicerces no trabalho desenvolvido.

Trata-se de aspectos que nos desafiaram a entender, a partir das narrativas das crianças, o que pensam sobre o que aprendem na escola. Neste texto, refletimos sobre lembranças e esquecimentos que remeteram a um tempo de produção do conhecimento que foi rememorado. O que consideramos foi a dimensão da experiência e dos sentidos que as crianças atribuíram para o que aprenderam. Constatamos que a literatura foi um elemento impulsionador considerado nas narrativas. Porém, os textos literários que promoveram esse processo foram aqueles que possibilitaram a emersão de aspectos lúdicos.

As narrativas evidenciaram, dessa forma, a força da ludicidade para os alunos e, por conseguinte, para o ensino. Os jogos e as brincadeiras tiveram um destaque evidente nas narrativas das crianças, o que permite repensar práticas escolares desenvolvidas, bem como a estruturação do módulo para os anos subsequentes. O desafio de romper com as amarras disciplinares já é uma possibilidade real na prática desse módulo. Todavia, repensar a metodologia por ele utilizada poderá enriquecer ainda mais as relações que as crianças podem estabelecer com o conhecimento histórico e geográfico.

A reflexão que aqui se apresenta é a de que é possível pensar uma prática pedagógica para o ensino dessas disciplinas nos anos iniciais do Ensino Fundamental, problematizada por diferentes pontos de vista, dialogando com as imagens projetadas nas diferentes instâncias sociais.

Compreendemos que as produções coletivas e individuais, oriundas das discussões em sala de aula a partir do portfólio, bem como o trabalho com as múltiplas linguagens, constituíram-se em fontes profícuas de pesquisa, que não se esgotam aqui. O que pretendemos com este texto foi trazer uma contribuição para o estudo do tema, a partir do olhar das crianças em diálogo com o dos pesquisadores, abrindo espaço para que novas pesquisas sejam elaboradas e para a importância de se considerar o protagonismo da criança no processo de ensino e aprendizagem. Crianças que, ao interagirem com o objeto de conhecimento, formulam ideias e buscam compreender o mundo ao seu redor.

\section{Referências}

ALMEIDA, Rosângela Doin de. Do desenho ao mapa: iniciação cartográfica na escola. São Paulo: Contexto, 2001. 
CHAVES, Iduina Mont'Alverne Braun. Histórias de vida e formação: cultura, imagens e simbolismos. Cadernos de Educação, Pelotas, v. 48, p. 87-107, maio/ago. 2014. Disponível em: <http://periodicos.ufpel.edu.br/ojs2/index.php/caduc/article/viewFile/4757/3540>. Acesso em: 5 mar. 2015.

COELHO, Nelly Novais. Literatura Infantil: teoria, análise, didática. São Paulo: Moderna, 2000 .

FRANCO, Camila; PIRES, Marcelo. Liga-desliga. São Paulo: Companhia das letrinhas, 2003.

FREIRE, Norma. A casa da Joaninha. Rio de Janeiro: B\&V, 1982.

FREITAS, Maristela Souza de; AGUIAR, Gersileide Paulino de. Educação e ludicidade na primeira fase do Ensino Fundamental. Interdisciplinar, Barra das Garças, n. 7, p. 21-25, 2012.

MELLO, Dilma Maria de; RODRIGUES, Ariane dos Santos; MACHADO, Nilma Nogueira. Professora ou maestra, sempre aprendiz/O Entrecruzar de minha vida pessoal e a vida na escola em minha formação/Pesquisa Narrativa: fenômeno estudado e método de pesquisa. In: ROMERO, Tânia Regina de Souza (Org.). Autobiografias na (re)construção de identidades de professores de línguas: o olhar crítico-reflexivo. São Paulo: Pontes, 2010.

MIRANDA, Sônia Regina; ALMEIDA, Fabiana Rodrigues de. Proposta curricular: História. Prefeitura Municipal de Juiz de Fora. Secretaria de Educação, 2010.

RAMOS, Anna Cláudia. Brincadeiras de todos os tempos. São Paulo: Larousse do Brasil, 2011.

SILVA, Amanda Maroco dos Reis. Literatura e ensino de História e Geografia: narrativas de crianças. 2014. 95 f. Trabalho de Conclusão de Curso (Especialização em Educação no Ensino Fundamental) - Universidade Federal de Juiz de Fora, Juiz de Fora, 2014.

STRAFORINI, Rafael. Ensinar geografia nas séries iniciais: o desafio da totalidade mundo. 2001. 155 f. Dissertação (Mestrado em Geociências) - Instituto de Geociências, Universidade Estadual de Campinas, Campinas, 2001.

VYGOTSKY, Lev Semonovich. A formação social da mente. São Paulo: Martins Fontes, 2007.

Camila Silva Pinho

Centro Federal de Educação Tecnológica Celso Suckow da Fonseca - Brasil Especialista em Educação no Ensino Fundamental Grupo Linguagens, Infância e Educação (LINFE)

E-mail: camilinhaspinho@gmail.com 
Dr ${ }^{a}$ Rosângela Veiga Júlio Ferreira

Colégio de Aplicação João XXIII - Brasil

Universidade Federal de Juiz de Fora - Brasil Doutora em Educação, Colégio de Aplicação João XXIII, Juiz de Fora

Grupo Linguagens, Infância e Educação (LINFE)

E-mail: rosangelaveiga.ferreira@ufjf.edu.br

Mestranda Andreia Cristina Teixeira Tocantins

Universidade Federal de Juiz de Fora - Brasil

Mestrado profissional em andamento em Gestão e Avaliação da Educação Pública

Licenciada em Geografia, Centro de Políticas Públicas e Avaliação da Educação, Juiz de Fora

Grupo Linguagens, Infância e Educação (LINFE)

E-mail: andreiatocantins@ hotmail.com

Recebido em: 05 de julho de 2016 Aprovado em: 12 de novembro de 2016 